\title{
A pouca atratividade da carreira docente: um estudo sobre o exercício da profissão entre egressos de uma Licenciatura em Matemática ${ }^{1}$
}

\author{
Romélia Mara Alves Souto*, Paulo Henrique Apipe Avelar de Paiva**
}

\section{Resumo}

Este artigo relata uma pesquisa sobre o perfil do professor egresso do curso de licenciatura em Matemática da Universidade Federal de São João del-Rei e aborda a questão da atratividade da carreira docente entre esses sujeitos, especialmente no magistério na educação básica pública. Professores de Matemática responderam a um questionário com perguntas objetivas e subjetivas e os dados obtidos foram analisados sob aspectos quantitativos e qualitativos. As análises revelaram preocupantes elementos sobre a atratividade e a permanência na docência e apontaram que quase a metade dos licenciados abandonou ou está prestes a abandonar o magistério. Confrontando os dados obtidos com os de outras pesquisas do gênero, chegamos à conclusão de que, até certo ponto, os entrevistados corroboram as estatísticas nacionais. Finalmente, alguns elementos sobre as raízes deste problema e alguns indícios sobre possiveis caminhos de superação são postos à reflexão.

\section{Palavras-chave}

licenciaturas; formação de professores; docência; carreira docente; licenciatura em matemática.
* Professora do Departamento de Matemática e Estatística e do Programa de PósGraduação em Educação da Universidade Federal de São João Del-Rei. Coordenadora de Gestão de Assuntos Educacionais do Programa Institucional de Bolsa de Iniciação à Docência (Pibid/ UFSJ). MG, Brasil. romelia@ufsj.edu.br

* * Graduando do curso de Matemática da UFSJ. Bolsista Pibic/UFSJ. apipep@yahoo.com 


\title{
The low attractiveness of the teaching career: a study of the profession among graduates in Mathematics
}

\begin{abstract}
This article describes a survey about the profile of the teacher graduated in Mathematics by Universidade Federal de São João del-Rei and studies the attractiveness of the teaching career among these people, especially in public basic education. The Mathematics teachers answered a questionnaire with objective and subjective questions and the answers were analyzed in their qualitative and quantitative aspects. The analysis shows worrying elements regarding attractiveness and permanence in the teaching career and shows that almost half of the teachers have quit or are about to quit teaching. By comparing the data collected in this study to other similar surveys, we have concluded that, up to a certain extent, the interviewees corroborate the national statistics. Finally, some elements about the reasons for this problem as well as some clues on overcoming it are presented for reflection.
\end{abstract}

Key words teaching training; teachers' education; teaching; teaching career; teaching degree in mathematics. 


\section{Introdução}

O trabalho que relatamos aqui aborda a questão da atratividade da carreira docente, tema relacionado ao problema de cativar e de manter professores qualificados atuando na educação básica. Esse tema tem ocupado cada vez mais espaço nas pesquisas educacionais, particularmente nos estudos sobre formação de professores. Nos últimos anos, não só no Brasil como em outros países, notamos a crescente preocupação de pesquisadores, de governos e de gestores de políticas públicas para a educação com o atual ou iminente déficit de professores em todos os níveis de ensino. Em nosso país, esse fato decorre fortemente tanto do abandono do magistério quanto da baixa procura dos jovens pela profissão de professor. Isso se explica, principalmente, pela pouca atratividade da profissão docente em relação a várias outras profissões que exigem o mesmo nível de formação acadêmica.

Na licenciatura em Matemática da Universidade Federal de São João del-Rei - UFSJ/MG, abservamos, a cada ano, o decréscimo no número de inscritos no processo seletivo do curso. 0 desinteresse pode ser constatado em várias outras licenciaturas da mesma Universidade e, também, na maioria das outras universidades. A baixa procura pelos cursos de Matemática não condiz com a significativa posição atribuída a esse componente curricular na educação básica. Dados do Censo Escolar 2007 (INEP/MEC, 2008), do ENADE 2005 (INEP/MEC, 2005) e do $\mathrm{CNE}^{2}$ (BRASIL, 2007) indicam que, se nada for feito, haverá falta de professores de Matemática para atender às redes escolares.

Nossa experiência na coordenação desse curso de Matemática, nas disciplinas básicas de Matemática e na orientação do Estágio Supervisionado, permite-nos acusar o manifesto desinteresse de muitos alunos pela profissão docente e a consequente desistência do magistério ainda nos anos finais da graduação. Em um levantamento que realizamos, recentemente, com os alunos matriculados no curso de Matemática da UFSJ, verificamos que, num universo de 94 alunos, apenas 53\% deles fizeram opção pela licenciatura movidos pelo desejo de ser professores. Quando nos restringimos apenas aos ingressantes em 2010, num total de 40 alunos, descobrimos que esse número é ainda menor: $32 \%$. Um dado que nos chamou particularmente a atenção mostra que, dentre os alunos que optaram pelo curso de Matemática, movidos pelo desejo de ser

2. INEP - Instituto Nacional de Estudos e Pesquisas Educacionais Anísio Teixeira; ENADE - Exame Nacional de Desempenho de Estudantes; CNE - Conselho Nacional de Educação. 
professores, apenas 50\% deles, ou seja, 25 alunos, afirmam que pretendem exercer futuramente essa profissão. Verificamos, portanto, que é muito alto o índice de desistência da profissão ainda durante o processo de formação inicial (Souto; Paiva, 2010). Esses dados, juntamente com os resultados de vários estudos sobre a atratividade da carreira docente, despertaram nosso interesse em conhecer os destinos dos profissionais egressos do curso de Matemática da UFSJ.

Para a realização da pesquisa aqui relatada, coletamos informações sobre o exercício da profissão e sobre o abandono do magistério entre os professores de Matemática formados na UFSJ. 0 estudo do caso do curso de Matemática pode nos ajudar a compreender a problemática que envolve o interesse e a permanência dos licenciados no exercício da docência, especialmente na educação básica pública e, consequentemente, a identificar os fatores que confluem para determinar a atratividade ou não da carreira docente.

A discussão sobre esse aspecto da carreira docente está em voga, atualmente, na literatura na área de formação de professores. Gatti (2009), ao relatar uma pesquisa que investigou o tema sob a ótica de alunos concluintes do Ensino Médio no Brasil, destaca, como fatores relacionados com a questão da atratividade da carreira docente, a complexidade do trabalho do professor e o aumento das exigências colocadas à atividade docente na atualidade. Alguns estudos analisam de que maneira as mudanças nos diversos setores da vida social, juntamente com as transformações nos sistemas educacionais, têm colocado em crise a identidade dos professores e, consequentemente, abalado a atratividade da profissão. Percebemos, atualmente, um distanciamento significativo entre a imagem ideal que professores constroem da sua função docente e a realidade de sua prática, não raras vezes decepcionante em razão da condição dos alunos, da escola e da sociedade. Fanfani (2007) afirma que a sociedade espera mais do que a escola é capaz de produzir e que as consequências disso são a decepção e o desencanto social em relação à escola e uma profunda sensação de mal estar no corpo docente, que se percebe como não estando à altura das exigências. A expressão "mal estar docente", cunhada pelo pesquisador espanhol José Manuel Esteve, em 1992, é amplamente utilizada na literatura, quando aborda a profissionalização docente, para caracterizar a insatisfação dos professores no magistério - tema de estudo cada vez mais frequente no Brasil e em outros países.

Lapo e Bueno (2003), ao examinarem a questão do abandono do magistério público na rede de ensino do estado de São Paulo, argumentam que isso se dá quan- 
do se frustram as expectativas do professor no confronto da realidade vivida com a idealizada. Segundo essas autoras, a rejeição da instituição escolar e da profissão acontece "quando as diferenças entre essas duas realidades não são passíveis de serem conciliadas, impedindo as adaptações necessárias e provocando frustrações e desencantos" (Lapo; Bueno, 2003, p. 75). As dificuldades encontradas pelos professores para lidar com a massificação do ensino; com os problemas de indisciplina e de violência; com a falta de sentido da escolarização para os alunos; com a introdução de novas tecnologias de ensino, aliadas à precarização do trabalho docente e aos baixos salários, concorrem para o abandono da profissão e explicam a decrescente atratividade da carreira na percepção dos jovens e dos próprios professores.

Valle (2006) acrescenta a todos esses fatores, responsáveis pela pouca atratividade da profissão, o fato de que o "exercício do magistério implica inevitavelmente a conciliação da atividade de ensinar e de outras que the são complementares, seja por sua natureza, seja em razão da organização do trabalho escolar” (Valle, 2006, p. 181). Percebemos que, à medida que aumenta a complexidade da atividade docente, diminui o prestígio social da profissão. Jesus (2004) atribui essa perda de prestígio social da profissão docente, entre outros fatores, à desvalorização do saber escolar e à baixa qualidade da formação acadêmica de muitos professores. Em um trabalho que discute a desmotivação e a crise de identidade entre docentes, esse autor considera que a perda de prestígio da profissão está ligada à alteração do papel tradicional dos professores, fazendo com que a escola deixe de ser considerada um meio de ascensão econômica e social. Além disso, esse autor destaca que "a profissão docente tornou-se pouco seletiva", ao permitir que muitos dos que ingressam na profissão "apresentem uma baixa preparação e, provavelmente, baixa competência profissional, para além de uma reduzida motivação para a profissão docente" (Valle, 2006, p. 195). Assim, o grande número de pessoas que exercem a profissão sem a adequada qualificação, ou mesmo sem qualificação alguma, ajudou a consolidar, para o senso comum, a imagem de que "qualquer um" pode ser professor. Essa crença traduz a percepção pouco clara da sociedade a respeito da função do professor. Segundo Lüdke e Boing (2004, p.1168-1169),

dentro do magistério a questão da identidade sempre sofreu as injunções decorrentes de uma certa fragilidade, própria de um grupo cuja função não parece tão específica aos olhos da sociedade, especialmente no caso dos 
professores do ensino elementar, a ponto de levar certos adultos a pensarem que qualquer um deles pode exercê-la. 0 grande número de pessoas que a exercem, com diferentes qualificações (e até sem nenhuma especificamente), também concorre para essa fragilidade, assim como o crescente número de mulheres, o que alguns autores consideram um traço das ocupações mais fracas, ou, no máximo, semiprofissões.

Ao tratar da precarização do trabalho docente, há quem acuse, inclusive, um retrocesso dos professores no sentido de uma "desprofissionalização". A decadência do magistério é percebida pelas famílias, pelos alunos, pela mídia e constatada pelos próprios professores que, desvalorizados socialmente, veem minada sua autoestima. A percepção da docência como profissão menor é generalizada e o sentimento de menos valia atinge, até mesmo, os futuros professores nos cursos de licenciatura. No modelo de universidade brasileira, as licenciaturas ocupam um lugar secundário:

A formação de professores é considerada atividade de menor categoria e quem a ela se dedica é pouco valorizado. Decorre daí uma ordem hierárquica naacademia universitária, as atividades depesquisa e depós-graduação possuem reconhecimento e ênfase, a dedicação ao ensino e à formação de professores supõe perda de prestígio acadêmico (Gatti; Barreto, 2009, p. 155).

Para alguns autores, o fator econômico se encontra na base desse processo de decadência do magistério. Lüdke e Boing (2004) consideram que o aspecto mais básico e decisivo, no processo de declínio da ocupação docente, está na decadência do seu salário e do que isso representa para a dignidade e para o respeito de uma categoria profissional.

Todos esses aspectos discutidos até agora devem ser considerados, ao analisar o preocupante índice de abandono do magistério. Eles trazem importantes elementos para a compreensão dos fatores que têm contribuído significativamente para modificar o perfil dos sujeitos que buscam a profissão docente e para diminuir sensivelmente o número de jovens que optam pelos cursos de licenciatura.

A literatura consultada sobre a atratividade da carreira docente reafirma, uma vez mais, a complexidade e a amplitude dos problemas da educação no Brasil. A 
dificuldade para cativar e para fazer permanecer na docência bons profissionais é apenas mais uma faceta desse intrincado panorama. Os estudos nos levam a crer que a educação brasileira, no momento atual, mais do que denúncias, carece de encaminhamentos rumo a soluções possíveis e necessárias para seus males. Nossos estudos têm mostrado que muitos alunos ingressam no curso de Matemática da UFSJ com objetivos alheios à docência, o que gera uma significativa diferença entre a quantidade de formados e os que, realmente, exercem a profissão (Souto; Paiva, 2010). Esses resultados podem ajudar a explicar o déficit de professores de Matemática para a educação básica. A pesquisa, que relatamos neste artigo, forneceu-nos dados importantes para melhor compreender a questão da atratividade da carreira docente a partir das experiências dos profissionais egressos do curso de Matemática da UFSJ e, então, levantar hipóteses e encaminhamentos para os cursos de formação de professores, que oferecemos.

\section{Metodologia}

Os sujeitos participantes da pesquisa foram os alunos egressos do curso de licenciatura em Matemática da UFSJ, num total de 96 pessoas - considerando os alunos formados até o início de 2010. Como instrumento de coleta de dados, utilizamos um questionário com 12 perguntas, sendo 2 abertas e 10 fechadas ${ }^{3}$. As questões fechadas tinham como objetivo levantar dados sobre a experiência profissional dos respondentes, a sua ocupação principal, o exercício do magistério em escolas públicas, a intenção de permanecer na docência, as expectativas a respeito do futuro profissional, a formação continuada do licenciado e também alguns aspectos socioeconômi$\cos ^{4}$. As duas questões abertas versavam sobre as dificuldades encontradas no exercício da docência na escola básica e sobre os motivos apontados para o abandono da profissão, quando fosse o caso. Para lançar luzes sobre o problema da atratividade da carreira docente entre os nossos licenciados, debruçamo-nos sobre as questões fechadas do questionário, as quais nos permitiram identificar, dentre os egressos do curso de Matemática, quantos estão efetivamente no exercício da docência, principalmente na rede de educação pública; quantos abandonaram a profissão sem nem mesmo tê-la experimentado; quantos desistiram da

3. Aproveitando a oportunidade do contato com os egressos do curso de Matemática, incluímos no questionário aplicado questões cujas respostas poderiam extrapolar 0 foco do problema, que nos ocupava naquele momento - 0 exercício ou o abandono da carreira docente. Esse procedimento deliberado visava à composição de um banco de dados sobre os egressos do curso que pudesse ser utilizado na pesquisa, que relatamos aqui, ou em futuras investigações.

4. Uma cópia do questionário encontra-se no Anexo deste artigo. 
carreira docente nos primeiros anos de exercício do magistério; quais os principais fatores que influenciaram na decisão de seguir ou não a carreira docente; e quais as perspectivas profissionais futuras daqueles que estão no exercício da profissão.

Para o levantamento dos dados, procuramos abarcar o maior número possível de ex-alunos. Inicialmente fizemos um primeiro contato telefônico com todos os egressos para explicar os objetivos da pesquisa e para solicitar a colaboração de cada um dos possíveis respondentes. A seguir, enviamos os questionários por e-mail, solicitando que fossem devolvidos também por e-mail. Em alguns poucos casos, por escolha dos participantes, o questionário foi respondido por telefone. Dos 96 egressos consultados, 67 responderam ao questionário, totalizando $69,8 \%$ do montante inicial. Como já mencionado, as respostas dadas às questões fechadas foram tabuladas, compondo um banco de dados que, submetidos à análise, produziram os resultados que apresentamos neste artigo. As respostas dadas às duas questões abertas são objeto de outro estudo - ainda em andamento - cujos resultados serão divulgados oportunamente.

Para chegar aos resultados que apresentamos aqui, procedemos a uma análise, que se constituiu em dois momentos. Primeiro, utilizando conceitos e métodos da Estatística Descritiva5 (Bussab; Morettin, 2009; Triola, 2008), os dados obtidos foram tratados e organizados em gráficos e tabelas, permitindo-nos proceder a uma análise quantitativa. Para a apresentação dos gráficos e tabelas neste artigo, seguimos as orientações dadas por Sabadini; Sampaio; Koller (2009). Num segundo momento, procedemos a uma análise qualitativa dos dados. Para isso, analisamos cada uma das respostas dadas às perguntas de um mesmo questionário, relacionando-as entre si, considerando, também, sua possível interação com as respostas dadas às perguntas correspondentes dos demais questionários. A análise qualitativa constitui-se, pois, num esforço de sucessivos movimentos de compreensão e de interpretação das respostas, que se dá na esfera da intersubjetividade. Nesse momento, articulam-se as concepções e as vivências prévias dos pesquisadores com os dados obtidos na literatura consultada sobre o tema, permitindo realizar inferências e tirar conclusões que, a nosso ver, respondem às indagações postas ao iniciar a pesquisa. Como em toda análise de cunho qualitativo, os resultados

5. Agradecemos à Profa. Daniela Carine Ramires de Oliveira pelas importantes sugestões dadas para 0 tratamento estatístico dos dados. obtidos carregam uma dose de subjetividade e os dados, que estão disponíveis, são passíveis de novas interpretações. 


\section{Resultados e Discussão}

\section{Identificação do grupo pesquisado}

Dentre os professores de Matemática egressos da UFSJ, que responderam ao questionário, a grande maioria é do sexo feminino - 71,6\%. No que diz respeito à faixa etária, $73 \%$ dos entrevistados encontram-se entre 22 e 30 anos de idade. A Figura 1 mostra a predominância desse grupo em relação aos outros. 0 curso de Matemática da UFSJ teve sua primeira turma de formandos em 2005 e a maioria das pessoas que ingressa no curso tem idade inferior a 25 anos. Portanto, no momento da realização dessa pesquisa, os docentes daqui egressos haviam concluído o curso há, no máximo, cinco anos.

\section{Figura 1 -}

\section{Idade dos professores de Matemática formados na UFSJ}

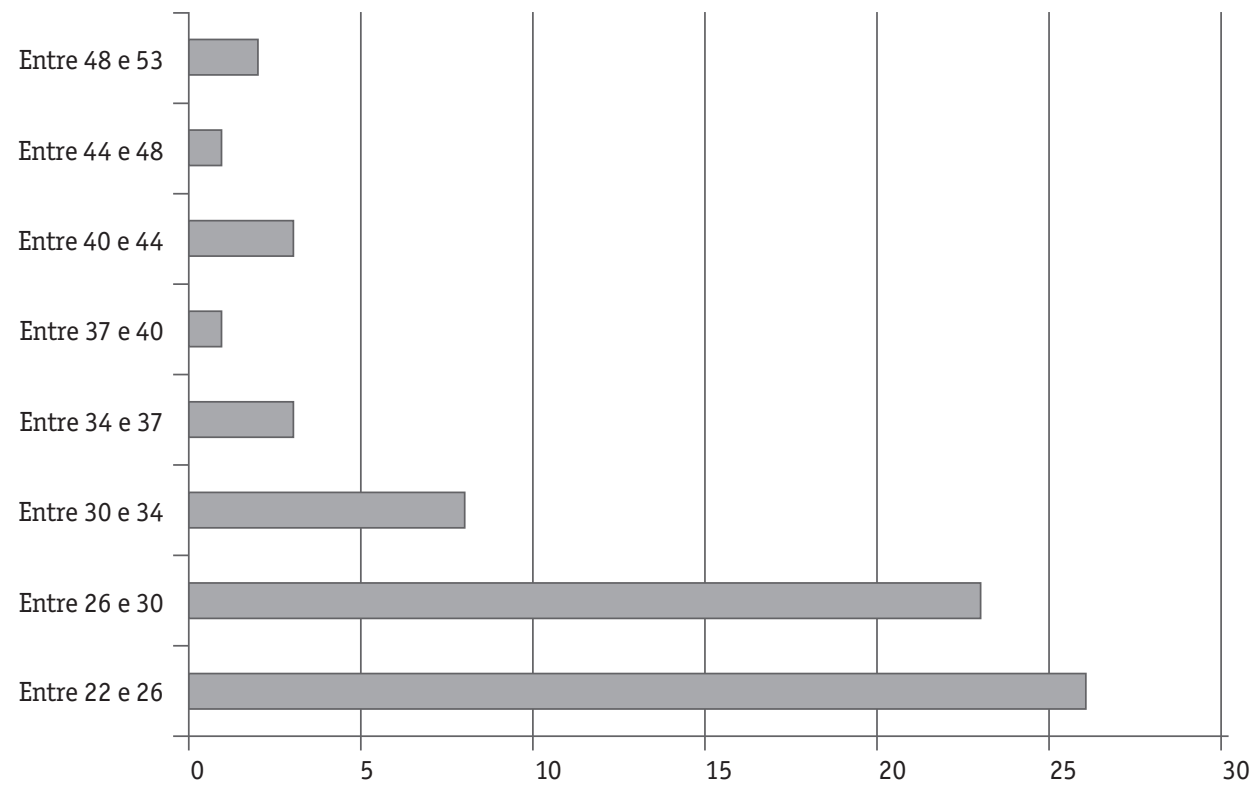

Fonte: Questionários utilizados para a realização desta pesquisa

O grupo de egressos pesquisados é constituído, em sua maioria, por indivíduos brancos $-79 \%$. Nenhum deles se declarou negro ou indígena. Levando em consideração que os respondentes se formaram entre 2005 e 2010, fica claro que, até aquele momento, no que diz respeito aos egressos do curso de Matemática, a UFSI rece- 
bia predominantemente alunos brancos, cenário que sabemos se repetir em outros cursos e em outras universidades públicas. Seria interessante observar as possíveis mudanças nesse quadro nos próximos anos, a partir da política de ampliação da oferta de ensino superior para as camadas menos favorecidas da população brasileira, implementada pelo governo atual e por seu antecessor.

Quase a totalidade dos egressos do curso de Matemática da UFSJ reside no estado de Minas Gerais, distribuindo-se de modo mais ou menos uniforme entre São João del-Rei, outras cidades do Campo das Vertentes e outras cidades mineiras fora da microrregião das Vertentes.

\section{Sobre a continuidade da formação dos licenciados}

A maioria dos licenciados que investigamos formou-se no biênio 2008/2009-43 concluintes. A média de alunos concluintes dos outros anos (seis) é, como se pode verificar na Figura 2, expressivamente menor.

\section{Figura 2 - Número de formados em Matemática na UFSJ}

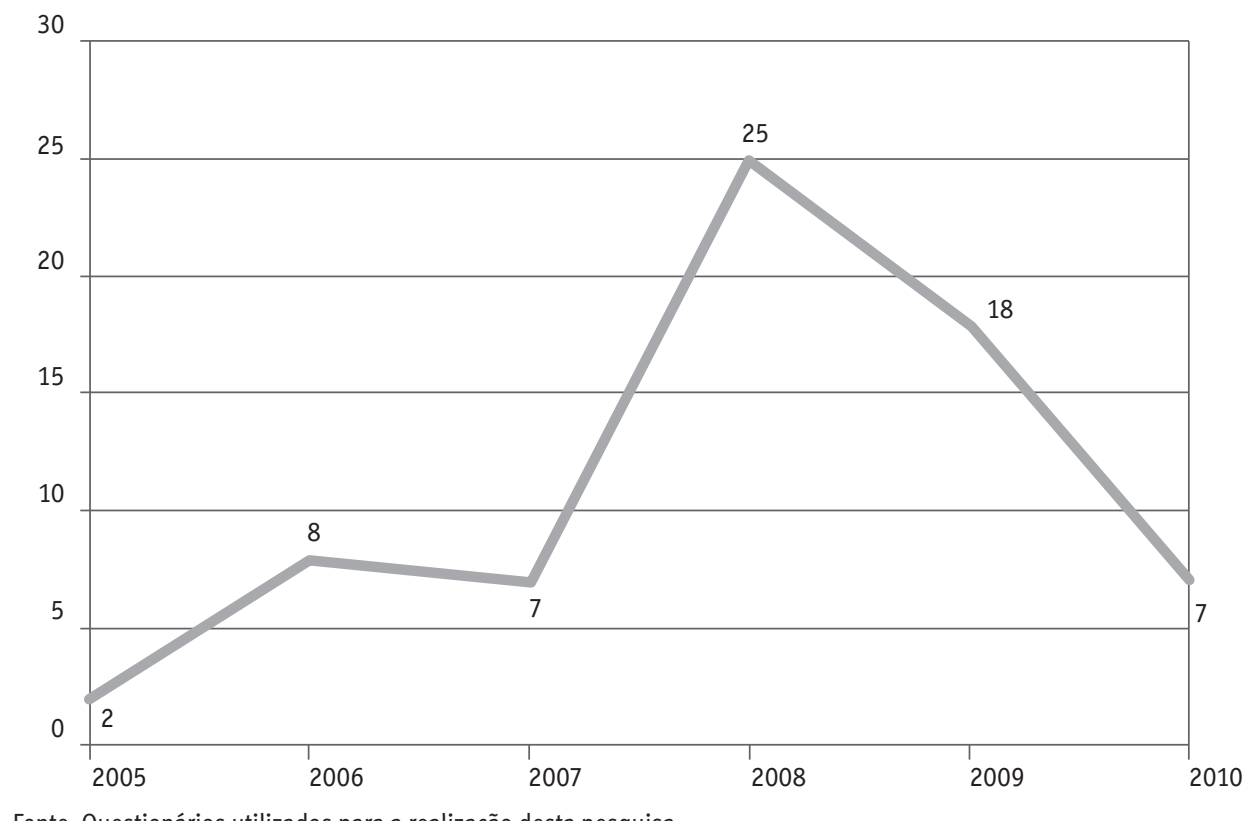

Fonte: Questionários utilizados para a realização desta pesquisa

Das 67 pessoas que responderam ao questionário, 36 declararam que estão es- 
tudando, 30 disseram que não estão estudando e uma pessoa não respondeu a essa questão. A maioria dos que estão estudando - $75 \%$ - optou por cursos de pós-graduação e dá continuidade aos seus estudos em instituições públicas, como mostram as Figuras 3 e 4 .

\section{Figura 3 - Nível em que o licenciado estuda}

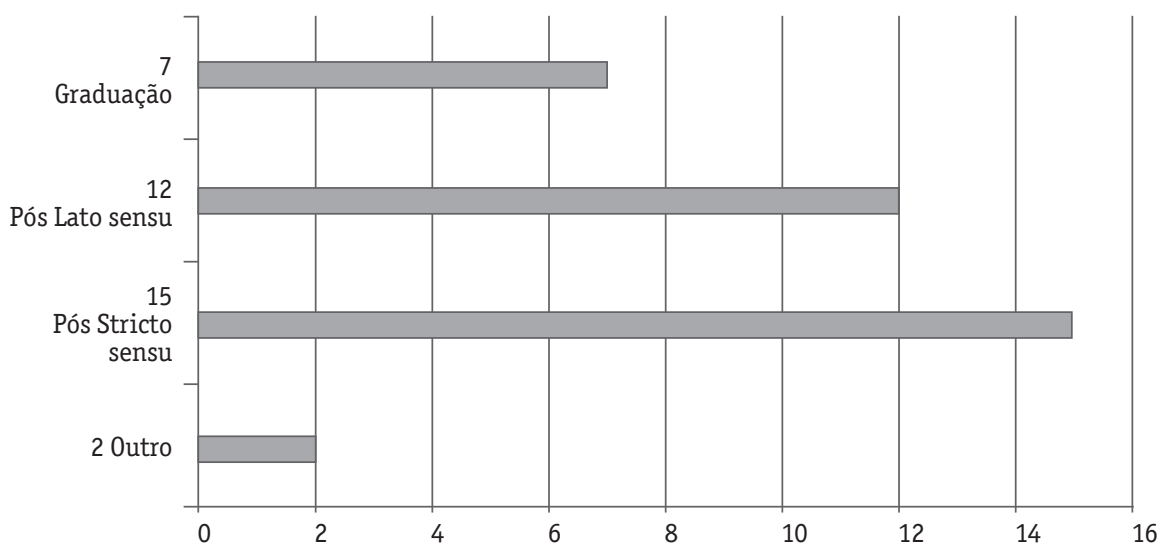

Fonte: Questionários utilizados para a realização desta pesquisa

\section{Figura 4 - Tipo de instituição que o graduado frequenta}

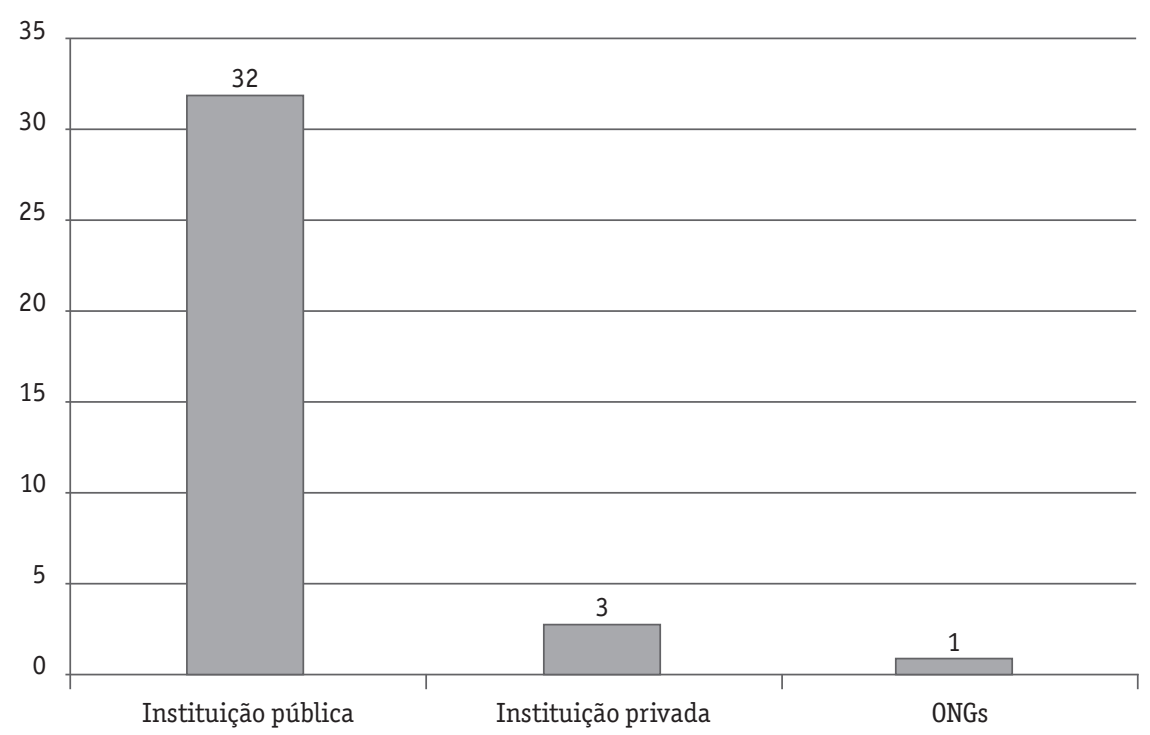

Fonte: Questionários utilizados para a realização desta pesquisa 
Ao analisarmos mais detidamente a opção dos licenciados pela pós-graduação, a intenção, nem sempre explícita, de abandonar o magistério ou de trocar o magistério na escola básica pelo o ensino superior ficou clara. Isso pôde ser percebido quando observamos a natureza dos cursos escolhidos por esses professores: áreas de Matemática pura ou aplicada, Estatística, Engenharia e Gestão Empresarial. A análise dos dados nos leva a crer que, dentre os licenciados que optaram pela pós-graduação lato sensu, nem todos têm a intenção de continuar lecionando no ensino básico. Podemos supor, também, que os egressos que fizeram a opção por outro curso de graduação tenham a intenção de mudar de profissão. Nesse último grupo (7 pessoas), apenas um escolheu um curso de licenciatura.

Ao serem indagados sobre a intenção de complementar a sua formação docente, 5 egressos, que estão exercendo a profissão, declararam não ter essa intenção. Outros 10 já abandonaram a profissão e, logicamente, não irão complementar a formação para a docência. Observamos que 10 egressos afirmaram não ter intenção de complementar sua formação docente e, no entanto, cursam pós-graduações em áreas afins à Matemática com vistas ao trabalho no ensino superior, conforme Figura 5 . É curioso observar que, mesmo pretendendo trabaIhar no ensino superior, esses licenciados não reconhecem seus estudos de pós-graduação como complementação para a formação docente. Dos entrevistados, 26 pessoas declararam continuar na profissão de professor de Matemática da educação básica e não estar estudando. Dentre os egressos que decidiram continuar seus estudos, apenas um está cursando mestrado na área de Educação Matemática, um cursa outra licenciatura e 12 fazem especialização em Matemática. Os demais (20) prosseguem seus estudos em áreas não relacionadas à docência. Esses dados nos levam a supor que a maioria dos que optaram por dar continuidade aos estudos o faz em busca de profissões mais rentáveis ou de uma carreira mais promissora, com condições de trabalho que se apresentam como melhores em relação às do professor da educação básica. 


\section{Figura 5 - Intenção dos egressos em complementar ou não sua formação docente}

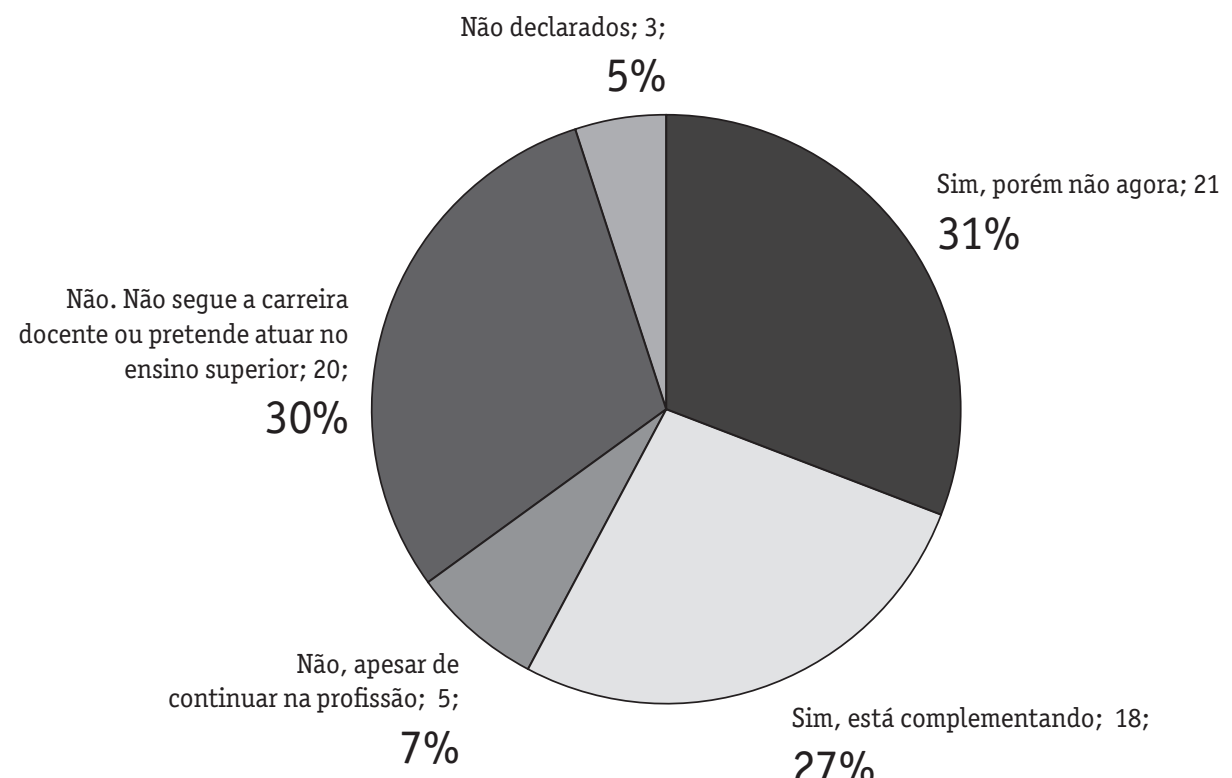

Fonte: Questionários utilizados para a realização desta pesquisa

\section{Sobre o exercício da profissão docente}

Dos 67 egressos pesquisados, 45 estão em efetivo exercício profissional, sendo que 3 deles atuam exclusivamente como tutores em cursos de graduação a distância. Assim, apenas 42 exercem a docência e a grande maioria, 78,6\%, é do sexo feminino. Coletamos informações sobre as esferas de atuação desses licenciados (pública ou particular), e também sobre a atuação em outras modalidades de ensino além da educação básica. A Figura 6 mostra que a grande maioria dos profissionais formados em Matemática na UFSJ está atuando no ensino básico público. Na categoria "outro" estão inseridos cursos técnicos, programas para alunos especiais, tutoria a distância e SENAC 6 . Observamos que é comum o professor lecionar em mais de um tipo de instituição, o que explica o número total de repostas (56) superior ao número de egressos em exercício (45).

6. Serviço Nacional de Aprendizagem Comercial - instituição de educação profissional aberta a toda a sociedade. 


\section{Figura 6 - Esfera de atuação dos licenciados}

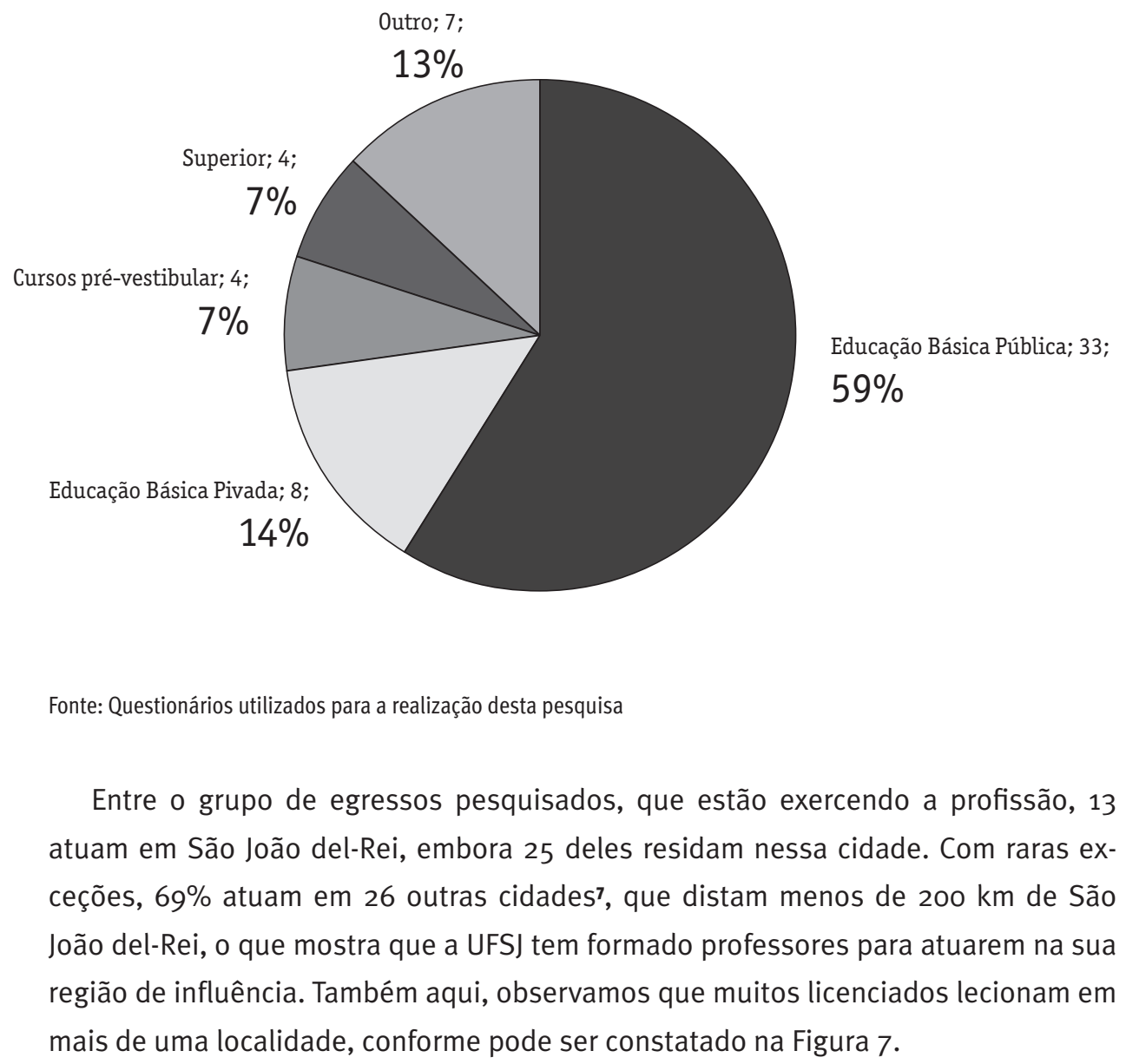

7. As cidades onde estão atuando os egressos são: Ouro Branco, Barbacena, Conselheiro Lafaiete, Belo Horizonte, Santa Cruz de Minas, Barão de Cocais, Barroso, Carandaí, Carmo do Cajuru, Congonhas, Contagem, Divinópolis, Entre Rios de Minas, Governador Valadares, Itacarambi, Jeceaba, Lavras, Mariana, Ouro Preto, Resende Costa, Ritápolis, Santa Bárbara, Santo André, Santos Dumont, São Gonçalo do Pará e São Tiago. À exceção de Santo André/ $\mathrm{SP}$, todas as outras cidades estão em Minas Gerais. 


\section{Figura 7 - Cidades onde os profissionais formados na UFSJ atuam}

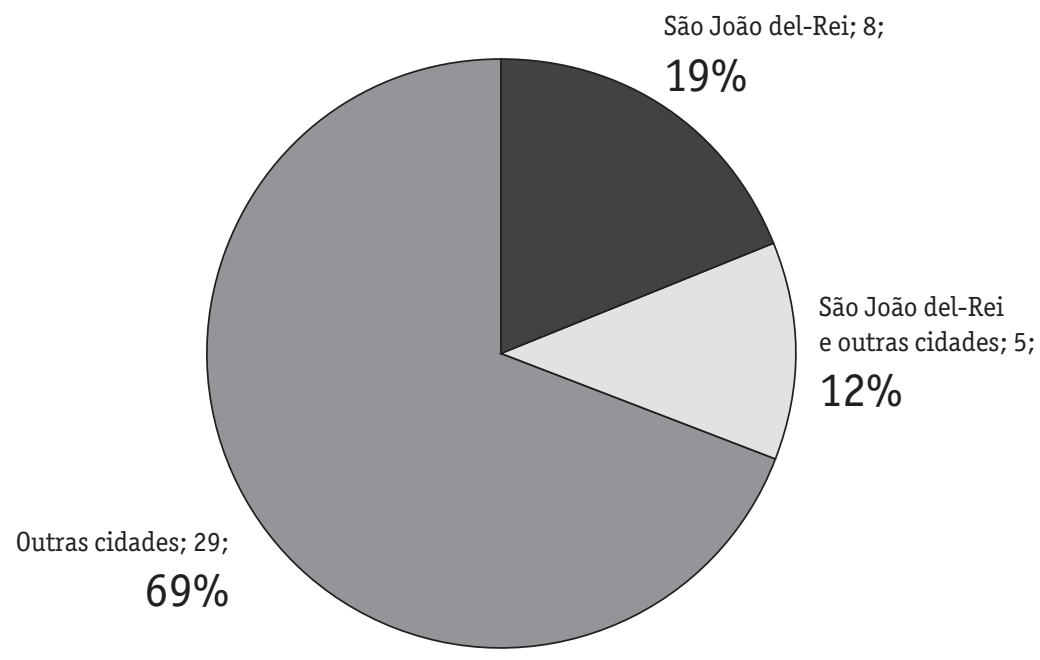

Fonte: Questionários utilizados para a realização desta pesquisa

Nos questionários aplicados, indagamos àqueles que estão lecionando sobre o grau de satisfação para com a profissão docente, enquadrando as respostas numa escala crescente de satisfação que variava de o a 10. A maioria dos egressos (33) atribuiu nota entre 6 e 9, sendo que 8 foi a nota mais frequente (14 respostas). Esse resultado denota que os licenciados estão, de certa forma, satisfeitos com a profissão. Uma pequena parte -8 respondentes - deu notas abaixo de 6 , sendo que a menor delas foi 2. Apenas um dos egressos, que leciona somente no ensino superior, mostrou-se estar plenamente satisfeito, atribuindo nota 10 ao seu grau de satisfação para com a profissão. É interessante notar também que, entre os professores que atuam na iniciativa privada, não foram atribuídas notas inferiores a seis. A Figura $8 \mathrm{e}$ a Tabela 1 sintetizam essas constatações. 
Figura 8 - Grau de satisfação dos egressos para com a profissão

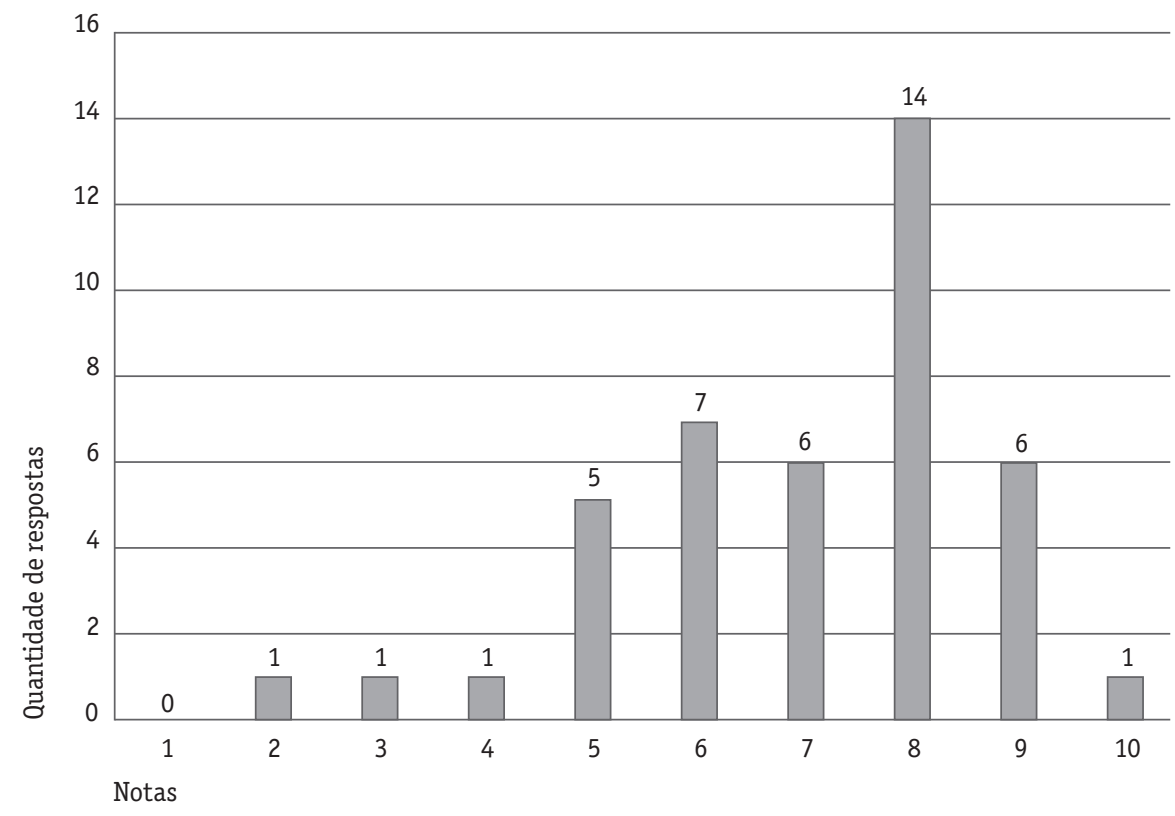

Fonte: Questionários utilizados para a realização desta pesquisa

A Tabela 1 exibe a quantidade de egressos que atribuiu cada nota para representar 0 grau de satisfação com a profissão, distribuídos de acordo com a modalidade de ensino.

Tabela 1 - Modalidade em que o professor atua versus grau de satisfação com a profissão

\begin{tabular}{|c|c|c|c|c|c|c|c|c|c|c|c|}
\hline \multirow[t]{2}{*}{ MODALIDADE } & \multicolumn{11}{|c|}{ NOTA ATRIBUÍDA } \\
\hline & 0 & 1 & 2 & 3 & 4 & 5 & 6 & 7 & 8 & 9 & 10 \\
\hline Ensino Público & & & 1 & 1 & 1 & 5 & 5 & 3 & 9 & 4 & 1 \\
\hline Ensino Privado & & & & & & & 1 & 1 & 2 & 1 & \\
\hline Ensino Público e Privado & & & & & & & 1 & & 3 & 1 & \\
\hline Outro & & & & & & & & 2 & & & \\
\hline
\end{tabular}

Fonte: Questionários utilizados para a realização desta pesquisa. 
Ao serem indagados sobre o desejo de continuar na profissão, 9 egressos - cerca de $21,4 \%$ dos que lecionam na educação básica - declararam que não pretendem continuar dando aulas nesse nível de ensino. Porém, estudando cada resposta, percebemos que esse número sobe para 19, se levados em consideração aqueles que cursam pós-graduação stricto sensu intencionando a carreira universitária. Portanto, o índice de licenciados que leciona no ensino básico, mas não pretende ali continuar, é de $45,2 \%$.

Os dados revelaram que 12 egressos já abandonaram definitivamente a profissão. Somando esse número com os 19 mencionados, no parágrafo anterior, concluímos que, dentre os 67 pesquisados, 31 não pretendem atuar como professores de Matemática na educação básica, o que mostra um alarmante índice de desistência da profissão nos primeiros anos de formados $-46,3 \%$. Numa primeira análise, parece incoerente haver uma taxa tão elevada de abandono da docência e, ao mesmo tempo, uma declaração quase generalizada de satisfação com a profissão. Podemos pensar, nessas circunstâncias, que não se trata exatamente de satisfação, mas de apreço pela profissão docente. Talvez, como é comum na classe dos professores, também os nossos licenciados percebam as atividades que exercem mais como uma "missão" ou "vocação" do que como uma prática profissional. E, apesar dos percalços e das contingências que os obrigam, muitas vezes, a buscar outras atividades profissionais, continuam valorizando a profissão de professor, atribuindo-lhe um mérito intrínseco.

Essa nossa hipótese mostrou-se plausível também, ao percebermos a dificuldade que muitos egressos parecem ter em admitir que pretendem abandonar a profissão. Uns afirmam que não desistiram da profissão, mas estão cursando, por exemplo, Engenharia ou Arquitetura, numa clara demonstração de que o abandono da profissão é uma possibilidade ainda não descartada. Outros se formaram e nunca exerceram a profissão, trabalham em outras áreas e, ainda assim, tentam justificar-se, dizendo que não abandonaram a profissão, mas estão apenas "esperando um pouco para ver se as coisas melhoram".

\section{Sobre as condições socioeconômicas dos egressos}

Levantamos também alguns dados sobre a situação socioeconômica dos egressos pesquisados, constatando que, na maioria das vezes, eles vivem com os pais (25) ou com o cônjuge (22). A renda familiar de 27 respondentes - cerca de 40\% - está entre $R \$ 1.200,00$ e $R \$ 2.500,00$, e $86,6 \%$ dos egressos possui uma renda familiar entre $R \$$ 
600,00 e $R \$ 5.000,00$. Considerando que se trata de renda "familiar" e que as famílias aqui tratadas são compostas, em sua maioria, por quatro pessoas, fica claro que a média salarial dos licenciados está muito abaixo da média salarial de outros profissionais com o mesmo nível de formação acadêmica. Esse perfil não difere muito do quadro que se apresenta em nível nacional, e sabemos que as condições de trabalho precárias a que são submetidos os professores brasileiros, aliadas à ausência de um plano de carreira promissor e aos baixos salários contribuem acentuadamente para a pouca atratividade da carreira para os jovens e para o abandono da profissão pelos que, ainda assim, a escolheram. Como mostra Gatti (2009), a carreira docente tem atraído principalmente jovens oriundos das classes menos favorecidas, para quem o magistério representa, ainda, alguma forma de ascensão social. No entanto, essa questão e outras suscitadas pelos egressos, quando indagados sobre as dificuldades encontradas no exercício da docência ou sobre os motivos que os levaram ao abandono da profissão, extrapolam o escopo deste artigo e serão tratadas de forma mais detida em outro trabalho.

\section{Considerações finais}

O perfil do egresso do curso de Matemática da UFSJ não difere muito do perfil do professor brasileiro. Num relatório com base nos resultados do Censo Escolar da Educação Básica 2007 (Brasil, 2009), entre as características do professor "típico" no Brasil, destacam-se a predominância do sexo feminino, de raça/cor não declarada, seguida pela raça branca e da idade média de 30 anos. Nesse estudo, foi-nos possível constatar, além disso, que a UFS forma professores de Matemática para atuarem na sua região de influência, na educação básica pública. Entre os pesquisados, notamos que $54 \%$ continuam os estudos. No plano nacional, segundo Gatti \& Barreto (2009), 23\% dos professores do ensino fundamental e 13,3\% do ensino médio declaram continuar estudando. Também, segundo essa mesma autora, a maioria absoluta dos professores $-97,7 \%$, em todas as modalidades da educação básica -, vincula-se ao setor público.

O foco do nosso estudo foi o exercício da profissão docente pelos egressos aqui considerados e, portanto, as informações mais relevantes foram sobre sua intenção de continuar na profissão de professor de Matemática, bem como sobre seu esforço por uma melhor qualificação profissional. Encontramos entre os nossos respondentes, um contingente expressivo de professores que não estão exercendo a profissão - 
25 pessoas (37,3\%). Entre os 42 docentes que estão em efetivo exercício, 9 explicitaram a intenção de não continuar na profissão. Entre os que exercem a profissão, há aqueles que estão atuando na educação básica e conjugando esforços para complementar sua formação para a docência. A maioria deles cursa pós-graduação em instituições públicas. 0 conjunto dos egressos que manifesta a intenção de abandonar a docência na educação básica ou de fazer dela uma atividade profissional secundária constitui quase a metade do grupo pesquisado. No estudo, já citado neste texto, em que traçamos um perfil dos alunos que cursam Matemática na UFSJ (Souto; Paiva, 2010), mostramos que é muito alto também o índice de desistência da profissão ainda durante o processo de formação inicial. Esses dados mostram que, para minimizar a falta de professores no ensino básico em todo o país, é preciso investir fortemente na carreira do magistério, tornando-a mais atraente do ponto de vista salarial. Isso contribuiria significativamente para modificar a representação social da profissão docente, possibilitando torná-la cativante para as novas gerações, especialmente para aqueles que se consideram em melhores condições de domínio de conhecimentos. As medidas de incentivo à criação de novas licenciaturas, de consolidação das já existentes e de programas de formação de professores que visam a regulamentar a situação daqueles que atuam no magistério sem a devida qualificação, implementadas pelos órgãos governamentais, são importantes e necessárias mas, nesse caso, não são suficientes.

Está claro que a falta de professores não se deve apenas ao reduzido número de profissionais egressos dos cursos de licenciatura, como fazem crer os sensos educacionais. Muitos dos futuros docentes desistem da profissão, já nos anos finais da licenciatura, desestimulados, principalmente, pelos baixos salários e pelas degradantes condições de trabalho a que são submetidos ao se dedicarem ao ensino básico em nosso país. 0 problema do abandono do magistério por graduados, em início de carreira, e a desistência da profissão por alunos que ingressaram recentemente no curso nos chama mais ainda a atenção, se observarmos que o licenciado em Matemática tem poucas oportunidades de trabalho fora da docência, diferente dos licenciados em Química ou Ciências Biológicas, por exemplo. O resgate do valor social do professor passa pelas questões desafiadoras da formação e da carreira docente, que estão contempladas em três metas do Plano Nacional de Educação - PNE (BRASIL, 2010), para a próxima década: a meta 15 , que trata da necessidade de garantir a todos os professores da educação básica formação específica de nível superior em curso 
de licenciatura na área de conhecimento em que atuam; a meta 17, que expressa a necessidade de aproximar o rendimento médio do profissional do magistério, com mais de 11 anos de escolaridade, ao rendimento médio dos demais profissionais com escolaridade equivalente; e a meta 18 , que trata da necessidade de implantar, num prazo de dois anos, planos de carreira para os profissionais do magistério em todos os sistemas de ensino. Para isso, é imprescindível a elevação dos investimentos em educação - o que também está previsto no PNE- , e alguma garantia de que o Plano deixará o papel e se tornará realidade até o ano 2020. 


\section{Referências bibliográficas}

BRASIL. Escassez de Professores para o Ensino Médio: propostas estruturais e emergenciais - Relatório produzido pela comissão especial instituída para estudar medidas que visem a superar o déficit docente no Ensino Médio. Brasília: CNE/CEB, 2007. Disponível em: 〈http://portal.mec.gov.br/cne/arquivos/pdf/escassez1.pdf〉. Acesso em: 25 maio 2011.

BRASIL . Estudo exploratório sobre o professor brasileiro com base nos resultados do Censo Escolar da Educação Básica 2007. Brasília: Inep, 2009. Disponível em: 〈http:// portal.mec.gov.br/dmdocuments/estudoprofessor.pdf〉. Acesso em: 12 abr. 2010.

BRASIL. Plano Nacional de Educação 2011-2020. Disponível em: 〈http://www.camara.gov.br/sileg/integras/831421.pdf $\rangle$. Acesso em: 22 maio 2011.

BUSSAB, W. O.; MORETTIN, P. A. Estatística Básica. 6. ed. São Paulo: Saraiva, 2009.

FANFANI, E. T. Consideraciones sociológicas sobre profesionalización docente. Educação \& Sociedade, Campinas, v. 28, n. 99, p. 335-354, maio/ago. 2007.

GATTI, B. A. et al. Atratividade da carreira docente no Brasil. São Paulo: Fundação Carlos Chagas, 2009. Relatório de pesquisa.

GATTI, B. A.; SÁ BARRETO, E. S. Professores do Brasil: impasses e desafios. Brasília: UNESCO, 2009. 293p.

INEP/MEC . Censo Escolar- 2007.

INEP/MEC. Microdados ENADE - 2005. CD-ROM.

JESUS, S. N. Desmotivação e crise de identidade na profissão docente. Katálysis, v. 7, n. 2, p. 192-202, 2004.

LAPO, F. R.; BUENO, B. O. Professores, desencanto com a profissão e abandono do magistério. Cadernos de Pesquisa, São Paulo, n. 118, p. 65-88, mar. 2003.

LUDKE, M.; BOING, L. A. Caminhos da profissão e da profissionalidade docentes. Educação \& Sociedade, Campinas, SP, v. 25, n. 89, p. 1159-1180, set./dez. 2004.

SABADINI, A. Z. P.; SAMPAIO, M. I. C.; KOLLER, S. H. (Org.). Publicar em psicologia: um enfoque para a revista científica. São Paulo: Associação Brasileira de Editores Científicos de Psicologia/Instituto de Psicologia da USP, 2009.

SOUTO, R. M. A.; PAIVA, P. H. A. Alunos da Licenciatura que não querem ser professores: traços do perfil dos estudantes do curso de Matemática da Universidade Federal de São João del-Rei. In: ENCONTRO NACIONAL DE EDUCAÇÃO MATEMÁTICA, 10., 2010, Salvador-Ba. Anais...Salvador: Sociedade Brasileira de Educação Matemática, 2010. 1 CD.

TRIOLA, M. F. Introdução à Estatística. 10. ed. Rio de Janeiro: LTC, 2008.

VALLE, I. R. Carreira do magistério: uma escolha profissional deliberada? Revista Brasileira de Estudos Pedagógicos, Brasília, v. 87, n. 216, p. 178-187, ago. 2006.

Recebido em 22 de novembro de 2011 e aprovado em o6 de setembro de 2012. 


\title{
Questionário do professor de Matemática
}

\author{
Nome / Idade / Cidade
}

1) Sexo: ( ) masculino / ( ) feminino

2) Você se considera

( ) branco

( ) negro

( ) pardo ou mulato

( ) amarelo (origem oriental)

( ) indígena

3) Ano em que se formou em Matemática na Universidade:

4) Se você trabalha como professor, assinale as alternativas que correspondem à sua situação.

Em que nivel você atua?

( ) Ensino fundamental público

( ) Ensino médio público

( ) Ensino fundamental privado

( ) Ensino médio privado

( ) Ensino superior

( ) Outro. Especifique

Você atua como professor

( ) apenas em São João del-Rei

( ) em São João del-Rei e outra(s) cidade(s). Especifique:

( ) em outra(s) cidade(s). Especifique:

Numa escala de 0 a 10, qual seu grau de satisfação para com a profissão de professor de Matemática?

( ) 0 ( ) 1 ( ) 2 ( ) 3 ( ) 4 ( ) 5 ( ) 6 ( ) 7 ( ) 8 ( ) 9 ( ) 10 
Você pensa em continuar na profissão?
( ) Sim
( ) Não. Por quê?

5) Se você não trabalha como professor, assinale a alternativa que contempla a sua situação .

( ) Já exerci a profissão, mas abandonei. Indique o tempo de exercício

( ) Já exerci a profissão e pretendo voltar a exercer. Indique o tempo de exercício

( ) Nunca exerci a profissão.

6) Você estuda?

( ) Sim. Especifique (nível e instituição)

( ) Não

7) Você tem intenção de complementar a sua formação docente?

( ) Sim, porém não agora

( ) Sim, já estou complementando

( ) Não. Exerço a profissão de professor de Matemática, mas não me interesso em complementar minha formação

( ) Não. Abandonei a carreira para seguir outra profissão

8) Em sua opinião, quais são as maiores dificuldades encontradas no exercício da docência em Matemática?

9) Se você abandonou a profissão, indique os principais motivos que acarretaram nessa decisão.

10) Você mora:

( ) sozinho (a)

( ) com os pais

( ) com cônjuge e/ou filhos

( ) outro. Especifique: 
11) Qual é, aproximadamente, a renda familiar total ( $R \$)$ ?

( ) Menor que 600,00

( ) Entre 600,00 e $1.200,00$

( ) Entre 1.200,01 e 2.500,00

( ) Entre 2.500,01 e 3.500,00

( ) Entre 3.500,01 e 5.000,00

( ) Acima de 5.000,00

12) Quantas pessoas são sustentadas com essa renda?

( ) Uma

( ) Duas

( ) Três

( ) Quatro

( ) Cinco

( ) Mais de cinco 